\title{
Policy Indications of International Experience for China's Emergency Response Mechanism Construction
}

\author{
Liyan Liu, Yongping Jing* \\ School of Economics and Management, Beijing Institute of Petrochemical Technology, Beijing, China \\ Email: ^jingyongping@bipt.edu.cn
}

How to cite this paper: Liu, L. Y., \& Jing, Y. P. (2021). Policy Indications of International Experience for China's Emergency Response Mechanism Construction. American Journal of Industrial and Business Management, 11, 887-904.

https://doi.org/10.4236/ajibm.2021.118054

Received: May 19, 2021

Accepted: August 10, 2021

Published: August 13, 2021

Copyright $\odot 2021$ by author(s) and Scientific Research Publishing Inc. This work is licensed under the Creative Commons Attribution International License (CC BY 4.0).

http://creativecommons.org/licenses/by/4.0/

(c) (i) Open Access

\begin{abstract}
The emergency management level is an important manifestation of the governance ability of a country. An effective emergency management mechanism can increase the speed of emergency response and minimize the damage of emergencies. In today's world, public safety emergencies frequently occur. Developed countries such as the United States, Japan, Russia, France, etc., have developed emergency management capabilities to effectively deal with emergencies after years of accumulation of experience. This research explored the practice of the emergency management system, emergency management legal system, digital emergency management technology, emergency management concept and emergency culture construction of the countries in the world to provide effective support for China's emergency management mechanism construction and related management decision-making. Based on the practical experience of developed countries, it is suggested that, first, the Chinese government should further strengthen the construction of emergency management mechanism; second, further improve the legal infrastructure of emergency management; third, accelerate the digital transformation of emergency management system; fourth, enhance emergency response to management philosophy and cultural construction.
\end{abstract}

\section{Keywords}

Emergency Management Mechanism, Policy Indications, International Experience

\section{Introduction}

As an important part of a country's comprehensive national strength, the gov- 
ernment's emergency response capability and management level have become an important indicator for evaluating its government's work and progress. The evaluation of the management level and ability of a government, not only depends on the performance of management and services under normal social and economic conditions, but more importantly, on how to respond to and deal with public emergencies under abnormal circumstances. How to improve the ability and level of emergency management to improve the suddenness, urgency, uncertainty, and universality of risk emergencies, and based on the diversification, expansion of scale, grouping of forms, and goals of emergencies in a risk society in the new era. Development trends such as internationalization are especially important. China's construction of emergency response mechanism started relatively late, and there are still problems in the formulation of emergency management policies, legal support, and awareness of emergency management, etc. It is beneficial for China to learn from international experience to further improve the construction of China's Emergency Response Mechanism.

In this context, this research aims to deeply explore some of the more advanced international experience and practices in public emergency management to provide ideas and support for improving the ability and level of emergency management of Chinese governments at all levels.

\section{International Experience in Emergency Response Mechanism Construction}

\subsection{Emergency Management System}

1) U.S. emergency management system

From the initial decentralized management in the 1930s and 1940s to the current homeland security management covering the entire federal and local levels, emergency management in the United States has formed a powerful emergency management system after a century of development. After the Great Depression in the United States, the "National Emergency Council" established by Roosevelt's New Deal in 1933 was the first attempt by the U.S. federal government to deal with natural disasters in a systematic way. Its main responsibility was to deal with economic crises and rescue the victims of natural disasters. When the economy began to recover, the "National Emergency Management Committee" was renamed "Office of Emergency Management" in 1939 and functioned together with newly established Office of Civil Defense. The emergency management of this period reflects the coexistence of emergency management and civil defense management. In 1979, the Federal Emergency Management Agency (FEMA) was established to reorganize decentralized emergency management departments and projects. The establishment of FEMA marked the beginning of a more proactive and systematic track of the US emergency management system (Li, 2003).

After September 11 in 2001, the Bush administration established the Department of Homeland Security to coordinate emergency management. The United 
States officially launched the largest government reorganization plan in 50 years, established the Department of Homeland Security based on FEMA, and formed an emergency management system covering various emergencies. The Department of Homeland Security is the core department of the United States government's unified leadership of emergency management. It is formed by the merger of 22 federal government agencies, including the Federal Emergency Management Agency, the Coast Guard, the Bureau of Immigration and Planning, and the General Administration of Customs, with a staff of 208,000. There are many people, including 2500 FEMA personnel (Terry \& Stivers, 2002).

In addition to major disasters in the United States that are resolved and coordinated by the federal government, many relief services are provided by local governments. To facilitate communication and speed up emergency response, the Department of Homeland Security has 10 regional representative offices across the United States, which are mainly responsible for liaison with local emergency agencies. In an emergency, it is responsible for assessing the losses caused by crisis events, formulating rescue plans, and coordinating with local governments, organizing, and implementing emergency rescue.

2) Russia's emergency management system

Russia's crisis management power with the president as the core subject and the Federal Ministry of Civil Defense (Emergencies and Elimination of Consequences of Natural Disasters, EMERCOM) and other corresponding departments as the main force structure. The Ministry of Emergency Affairs was born in 1994 and belongs to the executive authority. It is the core of Russia's organization for handling emergencies and is solely responsible to the President. The Ministry of Emergency Affairs is one of the five "powerful" departments of the Russian government. The other powerful ministries are the Ministry of Defense, the Ministry of Internal Affairs, the Federal Security Agency, and the Foreign Intelligence Service. The Ministry of Emergency Affairs has departments such as the Department of Population and Territorial Protection, the Department of Disaster Prevention, the Department of Forces, the Department of International Cooperation, the Department of Radiological and Disaster Relief, and the Department of Science and Technology Management. At the same time, there are institutions such as the Forest Fire Fighting Institution Committee, the Flood Fighting and Disaster Relief Committee, the Ocean and River Basin Underwater Disaster Relief Coordination Committee, and the Rescue License Management Committee. Nationwide, there are 8 regional centers that are responsible for disaster relief activities in 89 states (Wen, 2003).

3) Australia's emergency management system

In terms of disaster management, Australia established a national disaster relief organization based on the original Civil Defense Agency in 1974 to perform the functions of fighting natural disasters and emergencies. The National Disaster Relief Organization is affiliated to the Australian Ministry of Defense. The National Disaster Relief Organization Canberra Command has a coordination 
room, called the National Emergency Coordination Center, to ensure that federal resources are used as needed. The National Emergency Coordination Center establishes a comprehensive computer database through the National Emergency Action Support System and is connected to the Internet. Its daily work is to supervise the situation reports of the Meteorological Bureau and the State Emergency Management Bureau. The National Disaster Relief Organization is responsible for the rescue and relief work in Australia through the implementation of guidance and support to the emergency management agencies of the seven states and territories of Australia. And each state and territories work within the framework of their own legislation and plans. The Australian National Disaster Relief Organization has played an active role in disaster relief. The organization convenes once a year a federally funded meeting attended by state and territorial emergency service directors. The content of the meeting included training, support, public awareness, communications, civil defense, and other issues.

In terms of emergency management, Australia's emergency management system is based on the state, divided into three levels: federal government, state, and local government. At the federal level, the Emergency Management Agency under the Australian Department of Defense is the main emergency management department of the federal government and is responsible for national emergency management. At the state level, each state has its own emergency management department, which initiates emergency plans at different levels by judging the nature of the emergency and the scope of its possible impact. However, the state emergency management department is the main body to handle emergencies. When the local government cannot handle the emergency, it will apply to the state government for rescue. If the incident exceeds the state government's ability to respond, it will apply to the federal government. However, the federal government usually provides guidance, funds, and material support to the state government, and does not directly participate in management.

4) Japan's emergency management system

From different aspects such as social security and natural disasters, the Japanese government has established a crisis management system with the Prime Minister as the highest commander of crisis management and is responsible for crisis management throughout the country. The Japanese government has established a national "Crisis Management Center" on the basement level of the prime minister's residence to command and respond to all crises. Many government departments in Japan have offices in charge of crisis management. In the event of an emergency, a countermeasures headquarters must generally be established in accordance with the cabinet meeting resolution. If it is a relatively serious issue or situation, the prime minister must personally serve as the head of the department and take command. In this crisis management system, the government also activates different crisis management departments according to different types of crises. The Central Disaster Prevention Council, chaired by the 
Prime Minister, is responsible for responding to natural disasters throughout the country. In addition to the Prime Minister and the Minister of Land, Infrastructure, Transport and Tourism responsible for disaster prevention, its members include other cabinet members and heads of public institutions (Gan, 1996).

5) The UK's emergency management system

In the United Kingdom, after a disaster, the government will designate a central department as the "leading government department" according to the nature and needs of the situation. This department generally does not replace the main role of local governments in crisis management, but is responsible for coordinating the actions of various departments at the central level, ensuring that the channels for communication between various departments and local governments are smooth, and collecting information to notify high-level government officials, Congress, the media, and the public, etc. The Central Government has a National Emergency Committee, which is composed of ministers and other officials. The secretary of the committee is responsible for appointing "leading government departments", and the committee itself convenes meetings under the auspices of the Secretary of the Interior when necessary to supervise the work of "leading government departments" in critical situations. In 2001, the National Emergency Secretariat was also established under the Cabinet Office to carry out daily tasks such as crisis policy formulation, risk assessment, department coordination, and personnel training, and to provide support to various government departments, especially the National Emergency Committee.

The local government has established an emergency planning agency under the charge of the "Emergency Planning Chief". This agency is responsible for early warning of regional crisis, formulation of work plans, emergency training, coordinating all forces during a disaster, effectively handling affairs, and consulting or seeking necessary support from the corresponding central government department. The central government has a National Emergency Committee, which is mainly responsible for responding to specific types of incidents, such as nuclear accidents, or major incidents whose impact exceeds the local scope, such as major terrorist attacks.

6) Emergency management systems in other countries

The Austrian government also attaches great importance to disaster prevention and emergency preparedness. In addition to establishing and improving relevant systems in the country, it also strengthens contacts and cooperation with the European Union, NATO and the United Nations, actively participates in the formulation of the "EU Disaster Handling Procedures Work Outline" and cooperates with all neighbors. The country has signed bilateral cooperation regulations on disaster handling assistance and humanitarian assistance. In terms of emergency warning, the Federal Early Warning and Warning Center has been specially set up. The center is mainly responsible for collecting intelligence information, identifying dangerous signals, searching for dangerous information sources, making correct judgments, and notifying the Ministry of Foreign Affairs and Information Bureau after approval, and working with experts. Study and 
formulate corresponding countermeasures to assist the federal government and state governments in minimizing losses. The center arranges officials and experts to be on duty 24 hours a day and is equipped with advanced equipment and facilities to receive and process all kinds of information in all directions. Federal Early Warning and Warning Center and Information Bureau, etc. Relevant units are connected to the network to instantly understand all disasters and events in the world and are connected to the European Union Radiation Protection Center and the Austrian Radiation Warning System to process radiological event information in real time. The center is also equipped with telex television and alarm systems, with 8000 alarms covering small towns across the country.

Canada established the Emergency Preparedness Agency in 1988, making it an independent public service agency to implement emergency management laws. The responsibilities of the Canadian Emergency Management Agency are: to formulate provincial emergency plans, establish appropriate emergency agencies, negotiate with the provinces, meet public requirements, reduce the impact of emergency incidents, provide information to the public in advance, implement consultants and implementation plans, host relevant research on emergency preparedness, coordinate the emergency preparedness plans of various federal agencies, and manage the National Emergency Preparedness Institute.

In the Netherlands, the national emergency management agency is in the Ministry of the Interior, the Civil Emergency Planning Bureau, which is mainly responsible for coordinating civil emergency plans and disaster relief measures. More than 700 municipal governments in the Netherlands are the primary responsible sectors for emergency rescue in the Netherlands. The municipal governments formulate a series of disaster relief and special action plans. In cities and towns with a population of 25,000 or more, the municipal government employs civil servants who are responsible for formulating disaster relief plans. The fire brigade is responsible for the main operational responsibilities of disaster relief management (Pan, 2003).

\subsection{Legal System of Emergency Management}

Emergency management legislation is the basis for the construction of an emergency management system. For frequent major disasters and accidents that cause serious damage to people's lives and property, it is even more necessary to build a special legal system to guide and protect them.

The United States is a country with a relatively developed legal system. After years of practical exploration, the United States has formed a relatively complete emergency management legal system. Hundreds of laws and regulations specifically for natural disasters and other emergencies have been successively formulated and are often revised according to changing circumstances. In 1950, the United States enacted the first emergency response law, the Disaster Relief and Emergency Assistance Act. In 1976, the US Congress passed the National Emergency Act, the second law to deal with public emergencies, and in 1977, Congress passed the Earthquake Disaster Mitigation Act. The Stafford Disaster Mi- 
tigation and Emergency Assistance Act, passed in 1988, gave FEMA authority in more areas. Most importantly, it also provided a powerful financial means to allocate budgets specifically to encourage disaster reduction. In 2001, the "Emergency Supplementary Appropriation Law of 2001" and the "Law on Authorization of the Use of Military Forces" were promulgated and implemented, followed by the enactment of the "Air Transportation Security and System Mobilization Law", the "Air Transportation Security Law", and the "Enhancing Border Security and Improving Entry Visa Law" "Public Health Security and Bioterrorism Threat Prevention and Response Law”, "Terrorism Risk Insurance Law”, etc. In November 2002, the "Homeland Security Law" was promulgated and implemented, the Department of Homeland Security was established, and the emergency counter-terrorism system was reorganized to respond to emergencies (Comfort et al., 2012).

The advanced nature of Japan's legal system is obvious to all. It is also the earliest country in the world to formulate disaster emergency management laws and regulations. In 1880, Japan enacted the Famine Reserves Act, which passed legislation to ensure sufficient food and material supplies in the event of a disaster and famine. According to the classification of defense (belonging to the category of state of war law) or non-defense (being in the category of non-state of war law), Japan decomposes the state of emergency into laws such as the "Responding to External Armed Attack Act" and the "Basic Law on Disaster Countermeasures." In response to possible large-scale earthquakes, the government has formulated the "Large-scale Earthquake Countermeasures Special Measures Act", which stipulates earthquake disaster prevention, response measures, information transmission, post-disaster reconstruction, and fiscal and financial measures to reduce losses caused by earthquakes.

The United Kingdom is a country with relatively developed case law in the world and a typical representative of the common law system. There are as many as 30 laws on emergency management. The first unified emergency law in the UK was the Domestic Emergency Act passed and implemented by the House of Commons in January 2004. Immediately afterwards, the UK formulated several laws and regulations related to emergency management, so that the UK's emergency laws and regulations can be coordinated with each other and form a system of its own.

Russia's emergency legal system is quite complete. Based on the Constitution and Emergency Law, more than 100 supporting federal laws, regulations, and many presidential and government decrees have been formulated. Its laws for responding to emergencies include the "Russian Federal State of Emergency Law", the "Russian Federation State of War Law", and the "Russian Federation Anti-Terrorism Law". After the emergency law was launched, it became a "mini-constitution" and was under its leadership There are also many specific departmental laws and regulations. The United Kingdom is a country with an unwritten constitution. Because the legal system is too fragmented, in January 2004, the House of Commons passed the "Domestic Emergency Act", which is 
intended to integrate existing special laws and rebuild a state of emergency centered on the bill. Legal System (O'Keefe, 2007).

Germany does not have a unified state of emergency law. The current state of emergency system was established by the 17th Amendment Act of the Basic Law in June 1968 (the so-called "Emergency Constitution"). According to the provisions of the Basic Law, it has been formulated successively a series of one-way methods.

France stipulated the emergency state system as early as the 1830 constitution, which not only clearly defined the government's administrative emergency power, but also specified the relationship between the government and the people in a state of emergency. The "State of Emergency Law" is promulgated in April 1955 and revised it in 1960. Its characteristic is to focus on stipulating the powers of the government and the obligations of citizens in a state of emergency (Petak, 1985).

According to the classification of defense (belonging to the category of state of war law) or non-defense (being in the category of non-state of war law), Japan decomposes the state of emergency into laws such as the "Responding to External Armed Attack Act" and the "Basic Law on Disaster Countermeasures." In response to possible large-scale earthquakes, the government formulated the "Law on Special Measures for Large-scale Earthquakes", which stipulated earthquake disaster prevention, response measures, information transmission, post-disaster reconstruction, and fiscal and financial measures. Reduce losses caused by earthquakes (Raadschelders \& Lee, 2011).

Through research on the emergency management legal system of the United States, Russia, the United Kingdom, Japan, and other countries, it is found that emergency management based on the law is one of the successful experiences of developed countries, and all functions of emergency management are given by the law. Most developed countries have a complete system of laws and regulations on disaster prevention and mitigation, and have made relatively clear regulations on major issues related to disaster prevention and mitigation and emergency response, such as the responsibilities of governments at all levels and even the people in emergency management; The establishment of emergency management organizations; the formulation of disaster prevention and mitigation plans; emergency procedures and responsibilities after disasters; special financial measures to support post-disaster reconstruction, etc.

\subsection{Digital Emergency Management Technology}

Many developed countries have begun to carry out related research on digital emergency management as early as the 20th century and have widely applied digital technology to the construction of emergency management systems in multiple fields.

The US government established the Federal Emergency Management Agency (FEMA) in 1979, and merged FEMA into the newly established Department of 
Homeland Security after the "September 11" incident and the anthrax incident in 2003 and became one of the four subordinate departments of Department of Homeland Security. In recent years, FEMA has mobilized many scientific and technological resources to carry out extensive scientific research and experiments and has established a unique information processing system and a multi-level laboratory response network across the country to provide necessary data, theory, technology, and equipment to effectively respond to various public safety emergencies. To further overcome the predicament that public data is scattered in various federal, state, or private institutions, which hinders data integration, the US federal government initiated the establishment of the "Work Unit and Home Address Vertical Dynamic System (LEHD)" big data project. LEHD comprehensively integrates census and corporate data and conducts diachronic and real-time query and analysis of population and employment data. After 2010, LEHD integrated natural and man-made disaster data, launched data applications for public emergency, and better played the value of data in the emergency management system. When a large-scale emergency occurs, LEHD can quickly analyze the number and characteristics of the affected population, to provide decision-making basis for the next emergency, evacuation and other deployment and even recovery plans (Chen, 2018).

Japan is a densely populated country with frequent occurrences of natural disasters, as well as a pioneer and model country in emergency management. Since the Kobe earthquake disaster in 1995, the Japanese government has been committed to using digital means to improve the emergency management model and has established a crisis management system based on geographic information system (GIS) and a general computer network. The system contains different subsystems. It is used to operate emergency management related functions such as disaster prevention, emergency rescue, post-disaster reconstruction, and damage assessment (Zare, 2012). In addition, between 2003 and 2007, Japan installed the world's most advanced earthquake and tsunami warning system, which is also one of the main parts of the Japanese government's crisis management system. Through big data analysis, the early warning system issued imminent earthquake warning and tsunami warning to citizens before the "March 11" earthquake broke out in 2011 and played an important role in the government's crisis management decision-making and emergency rescue (Chu, 2017). In the introduction of big data to respond to sudden public hazards, the Japanese government has continuously strengthened cooperation with media and communication companies: When disasters occur, emergency rescue teams organized by the government can analyze location data from mobile phones, car navigation systems, etc., to accurately Obtain information and quickly support disaster-stricken areas; victims can also learn about evacuation routes and traffic conditions in real time through wireless communication networks (Du \& Zhu, 2012).

Some Japanese media, such as the NHK channel, are also responsible for broadcasting early warning systems, disseminating disaster relief information, 
and guiding public opinion (Liu \& Luo, 2011). In helping the government apply digital means to prevent and control public health incidents, Google launched the "Google Flu Trends (GFT)" research project in 2008. In the United States, seasonal flu has led to an increase in the number of patients visiting the emergency department and hospitalization, which has put a lot of pressure on the already tense medical system. Many studies have also confirmed that the crowded emergency department and the delay of key treatments are related to the increase in mortality from influenza (Bernstein, 2009). The influenza pandemic poses a recognized serious threat to the U.S. medical infrastructure, while traditional surveillance methods, such as the "U.S. Influenza Outpost Provider Surveillance Network" established by the Centers for Disease Control and Prevention (CDC), rely on the collection of many indicators. Including clinical symptoms, virological laboratory results, hospitalizations, and mortality statistics, resulting in data reporting often lagging. Therefore, effective management of seasonal and pandemic influenza requires timely and accurate monitoring to detect the epidemic as early as possible. The initial version of the GFT project adopted a combined analysis of big data and small data, found the best match among 50 million search terms to fit 1152 data points, and monitored the countries reported in the United States influenza outpost provider network Compare and match flu data detected at the, region, state, and city levels, and establish 450 million sets of mathematical models to analyze the time and space relationship between the frequency of specific search terms and the spread of flu. In the first few weeks of the 2009 American H1N1 flu outbreak, Google conducted flu trend analysis and successfully predicted the spread of H1N1 in specific states and regions and provided effective and timely data information for public health agencies (Ge, 2013).

\subsection{Emergency Management Concept and Culture}

Some foreign developed countries attach great importance to the construction of emergency culture and raise public safety to the level of social culture. Gradually forming an emergency culture in society is a basic quality necessary for life and work, and through various education, training, emergency drills and emergency response activities to promote the precipitation of emergency culture in society, greatly improving the normalization of emergency management.

The changes in the emergency management system in the United States are the result of the continuous development of emergency management concepts. Before the 1930s and 1940s, emergency management was mainly based on special laws formulated by the parliament to provide support for the restoration and reconstruction of state and local governments; in the 1930s and 1940s, emergency management embodied civil defense and emergency management Co-existing systematic management; in the 1950s and 1960s, returning to the comprehensive management theory that focused on civil defense and combining peace and war (Reddick, 2011); in the 1970s and 1980s, the comprehensive 
emergency management paradigm was proposed Comprehensive emergency management model, as preparation, response, recovery and disaster reduction; in the 1990s, concepts such as adaptive teams and fragility were introduced to expand the sustainable development model of emergency management; the beginning of the 21st century-now, due to the September 11 terrorist attacks and based on the FEMA, the Bush administration's established the Ministry of Homeland Security, which is an emergency management system covering all types of emergencies. And a comprehensive national accident response plan has been proposed, and the concept of homeland security has been emphasized (Kwan, 2005).

The U.S. government conducts intensive training for all emergency rescue personnel through training centers and training bases established in various regions. All emergency personnel must participate in emergency management related training every year. It is also open to social organizations and individuals who voluntarily participate in the training. In the construction of emergency culture, disaster relief drills are one of the important methods. Governments at all levels must conduct drills for crisis-prone events every year. Actively use the Internet, television, telephone, radio, mobile phone text messages and other methods to send various emergency-related materials and messages to citizens, especially in the process of emergency incident handling, the media plays an important role in releasing information in a timely manner.

Like the concept of homeland security proposed by the United States, Russia and Japan have also established the Population and Territorial Protection Department and the Department of Homeland Security in the emergency management system, highlighting the emergency management concept of homeland security, from public security to national security, and from emergency management. Rise to the height of national management.

Japan is an island country with frequent occurrences of natural disasters. Through the personal experience of dealing with natural disasters, the whole society has formed a good emergency culture atmosphere of disaster prevention, response to disasters and indomitable reconstruction of homes after disasters. Through the general establishment of emergency education-related courses in primary and secondary schools, citizens are educated in emergency knowledge and emergency awareness and ability training from an early age. The Japanese government sets September 1 as a fixed "Disaster Prevention Day" each year and stipulates August 30 to September 5 as "Emergency Management Week". In addition, there are many disaster prevention experience centers in various regions, which are open to citizens free of charge, so that they can experience the real scene when a disaster occurs and learn about evacuation methods.

In short, emergency management as an independent subject has only been studied in recent years, but countries have continuously summarized effective management methods from their respective management practices. Although China's emergency management has made some achievements, it is still in its infancy. Therefore, emergency management must be strengthened to ensure the 
healthy and stable development of the economy and society.

\section{The Enlightenment and Reference of International Emergency Management Experience to China}

\subsection{Further Strengthen the Construction of Emergency Management System}

It is essential to establish a unified and specialized emergency management agency. For a long time, due to the limitation of the emergency management system in different categories, China has formed a single event type, such as accident, typhoon, rainstorm, flood, drought, earthquake, etc., a single disaster management model by sector and region, resulting in lack of a unified and effective emergency management command system.

One of the "features" of China's current emergency management system is that multiple policies, and the emergency management work are fragmented, which is not conducive to unified command and dispatch. On the face of it, the disaster management system that performs its own duties cannot form a unified force to respond to critical incidents in the face of the complex situation of multi-disasters, nor can it effectively allocate disaster relief resources scattered in various departments in a timely and effective manner (Zhao et., 2018). Therefore, to carry out the integration of disaster resources as soon as possible, the government must always play a leading role, build a unified disaster management, command, and coordination mechanism for the whole society, realize the transformation from single disaster reduction to comprehensive disaster reduction, and form a combined force for emergency management.

From the perspective of comprehensive management, drawing on the experience of foreign disaster emergency management agencies, my country should establish a unified and specialized emergency management agency. The specific plan is as follows: establish a comprehensive coordination department led by the main leaders of the State Council, deputy prime minister or state councilor to deal with various crisis events including natural disasters. This organization is set up independently and belongs to the sequence of government agencies; in this agency. A functional department specializing in dealing with natural disasters, such as the Natural Disaster Bureau, has been established. The main functions of this functional department are divided into two aspects: daily operation and emergency management. The daily operation of the comprehensive coordination department is to regularly convene experts to conduct early warning analysis of various crises including natural disasters that may occur within a certain period, report the research results to relevant leaders of the State Council regularly, and propose corresponding measures to respond to crisis events; at the same time, the Institutions should also establish a consultation system for major crisis events. The comprehensive coordination department mainly plays the role of early warning, monitoring, consultation, and business guidance in peacetime. Once a crisis event breaks out, it should immediately be transformed into a spe- 
cific command and coordination agency for the country to respond to relevant crisis events, and authoritatively allocate resources for crisis events that have occurred. Disaster prevention and reconstruction of disaster-stricken areas play a central role in coordinating relevant departments.

\subsection{Further Improve the Legal Infrastructure for Emergency Management}

To increase the speed of emergency response in crisis and ensure the effect of emergency response, all countries in the world, especially developed countries, attach great importance to the construction of emergency legalization. Formulate the basic law of emergency management and improve the legal system for emergency management. System and plan construction. As far as China is concerned, our country has enacted nearly a hundred laws and decrees related to disaster prevention and mitigation. Especially since 1978, many disaster-related laws have been promulgated, such as the Earthquake Prevention and Disaster Mitigation Law, the Flood Control Law, etc. (Fan, 1998), but there is no comprehensive and standardized basic law for emergency response management, which has caused many issues since there is no law to follow in dealing with emergency response problems. Policies and administrative measures are used to replace the function of law to a considerable extent and within a considerable range. China's current disaster reduction laws only cover few disasters, with non-specific contents and low operability, and basic disaster reduction plan and emergency management plan at all levels of the government are absent.

We believe that due to the complexity and mass of China's emergency management issues, there is an urgent need to formulate national basic laws for emergency management and improve existing laws and regulations to adapt the legislative work to my country's current and future disaster management needs:

1) Formulate a comprehensive "Basic Emergency Management Law" to become the "mini constitution" for emergency situations, command specific emergency management laws and regulations of relevant departments, and form a unified and systematic emergency management legal system; the "Basic Emergency Management Law" regulates governments at all levels, Responsibilities and obligations of organizations, groups and individuals in emergency work shall stipulate in principle the basic content, basic principles, management system, management organization and major policies of emergency management, and make clear provisions on the budget content related to emergency management.

2) Designate a national-level emergency management plan, leading the emergency management plans of various departments and local governments. The plan for emergency management at the national and local levels should be incorporated into the plan for national and local social and economic development, so that emergency management can be coordinated and unified with economic and cultural constructions at national and local levels.

3) Under the guidance of the overall national emergency management plan, 
designate the emergency management plans of relevant departments and local governments at all levels from top to bottom, and review, supplement, and improve the existing emergency management plans;

4) Formulate emergency plans for major emergency incidents at the national level and all levels of government, which are used to guide the government, relevant departments, various organizations in emergency response after major emergency incidents, coordinate actions, and reduce losses.

\subsection{Accelerate the Digital Transformation of the Emergency Management System}

In dealing with the new crown epidemic that broke out in early 2020, China has applied big data to track the spread of the epidemic (Xinhua Daily Telegraph, 2020), built a digital information platform, applied artificial intelligence to predict the development of the epidemic, and built an electronic health assessment system, such as a health code system, which proved to be incredibly helpful and efficient (Zhao \& Hu, 2021). But at the same time, issues such as data management capabilities, data sharing system, privacy information security also emerged (Xinhuanet, 2020). Drawing on international experience, China should devote itself to the following efforts:

First, speed up the top-level design of the digital emergency management system. Strengthen the collection, analysis, processing capacity and sharing mechanism of public data and information of government management departments. Through the comprehensive use of big data and information technology, improve the government's ability to quickly respond to public emergencies and improve related management decision-making systems. Accelerate the construction of an integrated, full-coverage emergency management big data application platform, and rely on the national data sharing and exchange system to achieve efficient disposal of major risks online monitoring, advance warning, rescue and prevention and control. The Ministry of Emergency Management of China shall establish a unified public data management agency and a hierarchical release system of basic emergency information after professional evaluation, strictly control the release of basic public emergency information, and the information released shall be based on the level of early warning, degree of harm and development Perform timely updates and follow-up to ensure the accuracy and timeliness of information release, and strengthen close monitoring and analysis of public opinion after the information is released.

Second, deepen the digital governance transformation reform of public management. Local governments at all levels should seize the opportunity of smart city construction and "urban brain" construction to further promote the digital transformation of public management. Government departments should encourage in-depth cooperation between existing government information platforms and data platforms of large Internet companies to improve data collection, storage, processing, and analysis methods. The daily management system and emergency command platform based on user data sources and facing the public 
service of the whole society should be added or improved. In the daily management module, through the real-time synchronization update of data flow, information flow, and resource flow, the construction of convenient and profitable Public service smart management system for citizens; in the event of a crisis, big data and Internet of Things information can be used for automatic monitoring and early warning, while recording the incident reporter, reporting time, hazard attributes and emergency management instructions, and effectively establishing emergency command The platform-based digital plan improves the government's emergency decision-making ability in response to public emergencies, and truly realizes the combination of peace and war in emergency management.

Third, promote the integration and sharing of public big data and the guarantee of data security. At present, the biggest crux of the digital transformation in the field of government public management lies in the difficulty of data interconnection among governments, departments, systems, and businesses at all levels, and there are many "data islands" in government data. The central government should strengthen the sharing and coordinating capabilities of public data resources, introduce data sharing models and data norms and standards in major public areas, improve the structural matching of differentiated data, and promote the interconnection of public information. In addition, intelligent management platforms at all levels should strengthen the synchronization planning and synchronization operation of data, information, network, and system security construction, forming a full life cycle security protection including data collection, transmission, storage, processing, application, sharing and supervision. Clarify the data security protection responsibilities of relevant subjects, strictly protect the privacy of citizens and enterprises, and do a good job in determining the confidentiality of public basic information. Strengthen cross-border data flow assessment and certification, deepen dialogue and interaction and pragmatic cooperation with countries and regions and relevant international organizations, and jointly respond to data risks and technical challenges that threaten public safety.

\subsection{Strengthening the Concept of Emergency Management and Cultural Construction}

Developed countries have always attached great importance to the construction of emergency management concepts and legal culture. For example, the United States attaches great importance to the formal training of emergency practitioners through professional training institutions and strengthens the public's emergency awareness through the promotion of public opinion. The United States has training centers or training bases in all states, cities, and counties across the country. These professional training institutions are also open to the outside world and can serve the society and provide commercial emergency training for enterprises, social organizations, and individuals. However, the United States mandates that emergency practitioners must participate in emergency-related training every year to improve their ability to respond to emergencies. The 
German government mainly started from three levels to strengthen the construction of emergency culture. The first is to conduct professional and systematic training for staff in different positions; the second is to conduct emergency training for emergency volunteer groups and individuals organized by social organizations; the third is to conduct emergency training for individual citizens. Japan is an island country, and Japan has always had more natural disasters than other countries. Therefore, Japan has always attached great importance to emergency defense education and publicity training. At present, throughout Japan, a good emergency response and post-disaster reassurance and reconstruction have formed an emergency cultural atmosphere.

The construction of China's emergency management culture is relatively slow. China should actively promote the construction of emergency management concept and emergency management culture and raise the construction of emergency concept and emergency culture to the level of national management. Governments and organizations at all levels should strengthen the cultivation and construction of emergency concepts and emergency culture, and gradually incorporate emergency culture into the economic and social life management system and cultivate it as part of the basic literacy of people's life and work. And by incorporating the concept and culture of emergency response into all stages of school education, social training, emergency drills, and various emergency activities, the concept and culture of emergency response are widely accepted by the society, and emergency management is normalized. As in Japan, emergency education modules are set up in primary and secondary schools to allow citizens to educate and cultivate emergency awareness and ability from an early age. And set up emergency management elective courses in university education to further promote the improvement of citizens' emergency literacy. At the same time, actively use the Internet, media, mobile phones, etc. to publicize and send various emergency basic knowledge and emergency related information to the public, set "Emergency Management Days" and "Emergency Management Weeks", as well as emergency experience centers, which are open to citizens for free. This kind of emergency experience activities allows the public to experience firsthand the real scene of emergency events and disasters and understand emergency methods.

\section{Conclusion}

This research is based on the practice of foreign emergency management mechanism construction, through the analysis of the emergency management system, emergency management legal system, digital emergency management technology, emergency management concept and emergency culture construction of the developed countries in the world, endeavors to provide effective support for the emergency management mechanism construction and related management decision-making of China. Based on the practical experience of developed countries, it is suggested that, first, the Chinese government should further 
strengthen the construction of emergency management mechanism; second, further improve the legal infrastructure of emergency management; third, accelerate the digital transformation of emergency management system; fourth, enhance emergency response to management philosophy and cultural construction.

At present, the construction of emergency management mechanism and the digital reform of emergency management are still in their infancy. It is foreseeable that with the further development of society and economy, with the further improvement of public governance capabilities, and the strengthening of the linkage of emergency management brought about by the acceleration of globalization, the process of emergency management mechanism construction will inevitably be further accelerated. Issues as the cross-country, cross-regional, and cross-domain coordinated handling of emergency emergencies of international concern, the digital governance mechanism of emergency management, especially international collaborative governance of public health emergencies will become a focus of attention in both academic research and practical world.

\section{Supporting Projects}

The Emergency Response Mechanism and Policy Analysis of the Beijing-Tianjin-Hebei Cooperative Response to Accidents and Disasters, Beijing Social Science Foundation (18GLB020)

\section{Conflicts of Interest}

The authors declare no conflicts of interest regarding the publication of this paper.

\section{References}

Bernstein, S. L., Aronsky, D., \& Duseja R. (2009). The Effect of Emergency Department Crowding on Clinically Oriented Outcomes. Academic Emergency Medicine, 16, 1-10. https://doi.org/10.1111/j.1553-2712.2008.00295.x

Chen, S. S. (2018). The Impact of Open Government Data on Emergency Management Practices in the United States. Library, No. 9, 39-43.

Chu, J. W., \& Chen, S. S. (2017). A Comparative Study on the Management Mechanism Innovation of the Chinese, American and Japanese Governments in Response to Emergencies under the Background of Big Data. Intelligence Theory and Practice, 40, 127-133.

Comfort, L. K, Waugh, W. L., \& Cigler, B. A. (2012). Emergency Management Research and Practice in Public Administration: Emergence, Evolution, Expansion, and Future Directions. Public Administration Review, 72, 539-547. https://doi.org/10.1111/j.1540-6210.2012.02549.x

Du, C. Q., \& Zhu, S. B. (2012). Research on Urban Public Safety Emergency Management Early Warning System Based on Technologies for the Internet of Things. Procedia Engineering, 45, 748-754. https://doi.org/10.1016/j.proeng.2012.08.234

Fan, B. J. (1998). Natural Disasters and Disaster Management in China. Heilongjiang Education Press. 
Gan, F. (1996). A Comparative Study of Crisis Management in Japan and the United States . Journal of Hangzhou University, No. 2, 12-16.

Ge, K. K. (2013). The Era of Big Data: Great Changes in Life, Work and Thinking (pp. 140-142). Zhejiang People's Publishing House.

Kwan, M. P., \& Lee, J. (2005). Emergency Response after 9/11: The Potential of Real-Time 3D GIS for Quick Emergency Response in Micro-Spatial Environments. Computers, Environment and Urban Systems, 29, 93-113. https://doi.org/10.1016/j.compenvurbsys.2003.08.002

Li, H. W. (2003). Enlightenment of the United States Federal Emergency Management Agency's Integrated Disaster Relief System for My Country's Disaster Prevention and Rescue Work. Safety, Health and Environment, No. 11, 18-23.

Liu, Y. N., \& Luo, X. (2011). Japan's Emergency Management Mechanism and Its Enlightenment to China: Taking the "March 11 Earthquake" as an Example. Journal of Beijing University of Astronautics (Social Science Edition), 24, 16-20.

O’Keefe, S. (2007). Looking Back, Moving Forward. Public Administration Review, 67, 5-6. https://doi.org/10.1111/j.1540-6210.2007.00807.x

Pan, R. J. (2003). Introduction to Foreign Emergency Management Agencies for Disaster Prevention and Relief. National Defense News.

Petak, W. J. (1985). Emergency Management: A Challenge for Public Administration. Public Administration Review, 45, 3-7. https://doi.org/10.2307/3134992

Raadschelders, J. C. N., \& Lee, K. H. (2011). Trends in the Study of Public Administration: Empirical and Qualitative Observations from Public Administration Review, 2000-2009. Public Administration Review, 71, 19-33.

https://doi.org/10.1111/j.1540-6210.2010.02303.x

Reddick, C. (2011). Information Technology and Emergency Management: Preparedness and Planning in US States. Disasters, 35, 45-61.

https://doi.org/10.1111/j.1467-7717.2010.01192.x

Terry, L. D., \& Stivers, C. (2002). Democratic Governance in the Aftermath of September 11,2001. Public Administration Review, 62, 16-17. https://doi.org/10.1111/1540-6210.62.s1.3

Wen, X. F. (2003). Russia's Early Preparations and Plans to Ensure that the Emergency System Is Not Chaotic. The British Emergency System Has a Clear Division of Labor. Peninsula Morning Post.

Xinhua Daily Telegraph (2020). The Pandemic Is Like a Big Test, with Trillions of Investment in the "Intelligence" of Smart Cities Did You Pass? https://www.wxnmh.com/thread-6986558\%20.htm

Xinhuanet (2020). 28 Provinces, Autonomous Regions and Municipalities across the Country Cooperate with Alibaba to Launch the "Digital Epidemic Prevention System". https://baijiahao.baidu.com/s?id=1657783000440303049\&wfr $=$ spider\&for $=$ pc

Zare, M., \& Afrouz, S. G. (2012). Crisis Management of Tohoku Japan Earthquake and Tsunami, 11 March 2011. Iranian Journal of Public Health, 41, 12-20.

Zhao, G. Y., Xin, S. T., \& Luo, L. B. (2018). Decentralization, Administration, and Service" Reform: Government Promises and Technological Changes: An Investigation of Zhejiang's "Run Once for Maximum" Reform. Journal of Gansu Institute of Public Administration, 20, 35-46.

Zhao, Z. X., \& Hu, B. B. (2021). Thought and Countermeasures on Digital Transformation of Emergency Management System. Science and Technology Management Research, No. 4, 183-190. 